Pedagogía y Saberes No. 50 Universidad Pedagógica Nacional

Facultad de Educación. 2019. pp. 227-229

\title{
El otro cuerno del Unicornio
}

\author{
Homenaje* \\ 40 años del Grupo de Historia de la \\ Práctica Pedagógica - GHPP
}

Alexander Ruiz Silva**

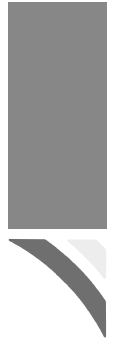

* Texto que conmemora los 40 años del Grupo de Investigación de Historia de la Práctica Pedagógica en Colombia. Presentado por el profesor Alexander Ruiz Silva en la ceremonia de inauguración de la Cátedra Doctoral 2018-II que se dedicó a la exposición de algunos de los trabajos doctorales de los investigadores que hacen parte del Grupo.

** Profesor de la Universidad Pedagógica Nacional; doctor en ciencias sociales e investigador del grupo Moralia.

Correo electrónico: alexruizsilva@yahoo.com Código ORCID: orcid.org/0000-0002-4671-1890 
S eguramente a todos nos ha sucedido que una experiencia que en un primer momento nos parecía simple o baladí, años después adquiere un valor superlativo. Así sucede a veces con el amor, con la amistad o con el comienzo de grandes obras, de aquellas que leemos o apreciamos, de las que somos testigos o, incluso, de las que - con éxito o no- nos hemos dispuesto a realizar. Otros asuntos caen en el registro de las cosas que pudieron ser. A estas últimas, Borges les hizo un hermoso poema que he querido incluir en mis palabras de homenaje a los amigos y colegas del grupo Historia de la Práctica Pedagógica, en la celebración de sus cuarenta años de existencia.

Pienso en las cosas que pudieron ser y no fueron.

El tratado de mitología sajona que Beda no escribió.

La obra inconcebible que a Dante le fue dado entrever,

ya corregido el último verso de la Comedia.

La historia sin la tarde de la Cruz y la tarde de la cicuta.

La historia sin el rostro de Helena.

El hombre sin los ojos, que no han deparado la luna.

En las tres jornadas de Gettysburg la victoria del Sur.

El amor que no compartimos.

El dilatado imperio que los Vikings no quisieron fundar.

El orbe sin la rueda o sin la rosa.

El juicio de John Donne sobre Shakespeare.

El otro cuerno del Unicornio.

El ave fabulosa de Irlanda, que está en dos lugares a un tiempo.

El hijo que no tuve. (Borges, 1996).

¿Y a quien le corresponde encontrar estas cosas? ¿Qué sentido tiene está búsqueda? ¿Con quienes emprender este camino? Las personas que hoy son objeto de homenaje llevan muchos años en busca del otro cuerno del Unicornio; de entre ellos, los más realistas, se han conformado solo con buscar al Unicornio.
Pero, ¿qué les ha permitido mantenerse como grupo durante tanto tiempo? Quizás el azar de sus encuentros; la confluencia de intereses; los propósitos comunes imaginados, inventados; la distinción arbitraria del nosotros-ellos y, a pesar de las íntimas enemistades - que nunca faltan-, una perversa inclinación a mantenerse juntos. Me aventuro a pensar que también la gratuidad de la amistad y una indudable inclinación estética en la elección de las lecturas.

El Grupo, como les he oído referirse a sí mismos cuando se aluden en conjunto, no es, ni de cerca, la suma de sus producciones o una presencia incorpórea permanentemente invocada de distintas formas o un impulso creador sostenido por el espíritu mismo de la perseverancia - que es una forma sofisticada de decir que la mayoría de sus miembros son real y comprobadamente tercos-; no, no es ninguna de estas cosas por separado, son todas ellas juntas, artesanal y amorosamente vinculadas.

Los buenos matrimonios no suelen durar tanto; los malos en cambio sí y si se descuidan pueden incluso superar las cuatro décadas. Por lo visto, El Grupo está dispuesto a asumir este tipo de descuido, con tal de seguir pensando y creando. Debe ser la más fecunda y extraordinaria unión de las peores que conozco.

Lo que en Colombia y en América Latina se entiende por educación y pedagogía se debe, en buena medida, a su producción escritural; lo que hoy conocemos respecto al saber pedagógico, se debe a ellos casi en su totalidad. Y lo que aún hace falta, que no quepa duda, lo están encarando arqueológicagenealógicamente en su misma configuración; de no poderse de este modo, lo harán, supongo, deleuzianamente fuera de campo.

¡Está claro, no sueltan presa! Son auténticos cazadores de unicornios, y aunque no desprecian nunca el resultado están más interesados en la aventura. Les propongo dar un pequeño rodeo por la historia de la bella bestia, para luego volver a los cazadores, que son quienes más nos interesan ${ }^{1}$.

$\mathrm{Al}$ igual que sucede con otros animales fantásticos como los basiliscos, grifos y dragones, los principales atributos de los unicornios yacen en la ima-

1 He tomado algunas referencias sobre los unicornios del libro que recientemente escribí junto a Manuel Prada: Didáctica de la fantasía. La formación del niño como sujeto de derechos (en busca de editor). 
ginación humana. Entre mitos y leyendas se ha ido decantando la forma de un hermoso caballo blanco, con patas, barba y cola de otros animales y un largo y poderoso cuerno en la frente. Convengamos, por ahora, en esa imagen arquetípica y centrémonos en la magia que la palabra ha ido creando en torno suyo, a través del tiempo.

En la Edad Media, fascinados por las historias sobre la gracia, belleza y escasez de los unicornios y los poderes atribuidos a su cuerno en espiral, viejos reyes, príncipes herederos, señores feudales y jerarcas de la Iglesia obsesionados con una longeva existencia y con la obtención de un remedio efectivo contra el veneno de potenciales traidores, encomendaron a fieles militares y mercaderes viajar grandes distancias - a la India, especialmente - en busca de los afamados animales. Por supuesto, el propósito era cazarlos y cortarles el cuerno, con el que, luego de triturado, se pudiera rociar los alimentos de la perennidad.

Un fragmento de la novela El unicornio de Manuel Mujica Lainez nos ayuda a enfatizar lo dicho sobre el cuerno de este excepcional ser. Allí enfatiza, que se trata de un

talismán precioso, que solía esconder en su base un carbúnculo curativo de enfermedades, poseía la virtud de preservar contra los sortilegios y de ennegrecerse al entrar en contacto con cualquier materia venenosa. Por eso lo árabes incrustaban un trozo [del cuerno] del unicornio - cuando lograban, a cambio de bolsas de oro, conseguirlo- en los mangos de los cuchillos que empleaban en sus festines. En este caso, si la comida era tóxica, un leve sudor informante cubría la hoja de metal. Por eso tuvo uno Lorenzo el Magnífico. Y es fama que si el monoceronte lo hundía, al beber, en el agua de un río, el líquido hervía, formando una nívea espuma que hacía huir a las alimañas mortíferas; entonces los demás animales aprovechaban para beber por turno y el unicornio benéfico quedaba aparte. (Lainez, 1979, p. 38).

Es de suponer que en dicha época las grandes cantidades de dinero destinadas a financiar estas expediciones hicieran progresar ostensiblemente la industria del fraude, aunque, de paso, las mismas aventuras contribuyeron a que la astucia se hermanara con la imaginación. De esta relación proceden las historias sobre la gran fuerza, velocidad y fiereza del unicornio y la probada dificultad para cazarlo. Esta misión solo podía facilitarse mediante la participación, en la cacería, de una joven y virginal doncella. Ella debía caminar serena por el bosque hasta lograr atraer y apaciguar a la esquiva bestia. Así, ante la caricia de otro ser bello e inocente, el unicornio se hacía más vulnerable a la presencia de las sogas, las trampas y las armas.

De esos bosques de palabras y sensaciones emergen los cazadores de esta historia. Ellos se han encargado de exaltar en el archivo el valor del detalle; los asuntos periféricos, aparentemente intrascendentes; lo cotidiano por muchos despreciado; lo imaginario, lo imaginado, esto es, la realidad que no se agota en existencia. Se trata de un trabajo rigurosamente sostenido en el tiempo, con enorme convicción y gran vitalidad.

Pero acaso esta figura de los poderes curativos del cuerno nos sirva para pensar en la fuerza terapéutica de la palabra hecha vida, diálogo, personajes y acciones que podemos hallar en los escritos de los miembros de El Grupo; en los múltiples aprendizajes que extraemos de su experiencia; en los nuevos desafíos que plantean sus renovadas lecturas y escrituras. Es como si el cuerno de la palabra que circula en la enseñanza se hundiera en las aguas turbias del mutismo, la invisibilidad, el agotamiento, la esterilidad, y de pronto todo se hiciera menos vago, más claro, más preciso: este es, a mi juicio, el otro cuerno del Unicornio, un legado que hoy tenemos oportunidad de agradecer y celebrar. Felicitaciones y gracias por tanto.

Bogotá, 21 de agosto de 2018

\section{Referencias}

Borges, J. (1996). Things that might have been. En Historia de la noche (Obras completas, tomo III). Buenos Aires: Emecé.

Mujica, M. (1979). El unicornio. Buenos Aires: Sudamericana. 